\title{
Regulatory mechanism of melatonin on the retinal ganglion cell photoreaction in mice
}

\author{
JIANQIAO LI ${ }^{1}$, JIONGWAN HONG $^{1}$, FANG ZHOU $^{1}$, SHIBO TANG $^{2}$ and XINYI WU ${ }^{1}$ \\ ${ }^{1}$ Department of Ophthalmology, Qilu Hospital of Shandong University, Jinan, Shandong 250012; ${ }^{2}$ State Key Laboratory of \\ Ophthalmology, Zhongshan Ophthalmic Center, Sun Yat-Sen University, Guangzhou, Guangdong 510060, P.R. China
}

Received May 6, 2016; Accepted October 7, 2016

DOI: $10.3892 /$ etm.2017.4672

\begin{abstract}
The study aimed to analyze the regulatory mechanism of melatonin (MLT) on the retinal ganglion cell photoreaction in mice. Forty-eight, 3-week-old healthy ICR mice, regardless of gender, were randomly divided into 4 groups. Group A was exposed to an illumination/dark time of $0 \mathrm{~h} / 24 \mathrm{~h}, 6 \mathrm{~h} / 18 \mathrm{~h}$ in group B, $12 \mathrm{~h} / 12 \mathrm{~h}$ in group $\mathrm{C}$ and $18 \mathrm{~h} / 6 \mathrm{~h}$ in group D, for up to 6 weeks. Four mice in each group were sacrificed at week 1, 3 and 6, respectively, for harvesting of retinal ganglion cells. ELISA was used to detect nocturnal plasma MLT levels at midnight. Immunohistochemistry was used to detect the expression of the retinal MLT receptor and the expression levels of inducible nitric oxide synthase (iNOS) and c-fos protein. The plasma MLT levels, MLT receptor levels and c-fos protein expression levels of group C, after 1, 3 and 6 weeks of light application, were the highest, followed by groups B and D, while group A had the lowest levels. For each illumination time, the iNOS levels of group $\mathrm{C}$ were the lowest and group A was the highest. Differences were all statistically significant $(\mathrm{P}<0.05)$. In conclusion, appropriate illumination regimens can increase c-fos protein, decrease iNOS activity and regulate the physiological activities of the retinal ganglion cells by regulating the expressions of MLT and its receptor.
\end{abstract}

\section{Introduction}

Melatonin (MLT) is a neuroendocrine hormone produced by the pineal gland under physiological conditions and is regulated

Correspondence to: Professor Shibo Tang, State Key Laboratory of Ophthalmology, Zhongshan Ophthalmic Center, Sun Yat-Sen University, 54 Xianlie Road, Guangzhou, Guangdong 510060, P.R. China

E-mail: shibo_tang1@163.com

Dr Xinyi Wu, Department of Ophthalmology, Qilu Hospital of Shandong University, 107 Wenhua Xi Road, Jinan, Shandong 250012, P.R. China

E-mail: xywu8868@163.com

Key words: melatonin, retina, ganglion cells, photoreaction, inducible nitric oxide synthase, $\mathrm{c}$-fos protein by the suprachiasmatic nucleus, according to the circadian rhythm (1). MLT can regulate circadian rhythms, the sleep and wakefulness circadian phase and improve sleep (2). According to recent studies, MLT also plays an important role in anti-oxidative stress, as well as in anti-inflammatory and anti-apoptotic processes (3). The MLT receptor is widely distributed in retinal ganglion cells, and it may be involved in the formation of light reaction pathways and all forms of retinopathy (4).

The present study aimed to analyze the regulatory mechanism of MLT on mouse retinal ganglion cell photoreaction.

\section{Materials and methods}

Animals. A total of 48 healthy, 3-week-old ICR mice (male or female), weighing 7.2 $\pm 1.3 \mathrm{~g}$, were purchased from Charles River (Boston, MA, USA). The mice were maintained at conventional breeding temperature $\left(23 \pm 2^{\circ} \mathrm{C}\right)$ and relative humidity $(55 \pm 5 \%)$. The animals were then randomly divided into 4 groups. Group A had an illumination/dark cycle of $0 \mathrm{~h} / 24 \mathrm{~h}$, group B had $6 \mathrm{~h} / 18 \mathrm{~h}$, group C had $12 \mathrm{~h} / 12 \mathrm{~h}$ and group $\mathrm{D}$ had $18 \mathrm{~h} / 6 \mathrm{~h}$. The dark condition was breeding room brightness $<0.0004 \mathrm{~cd} / \mathrm{m}^{2}$. The mice underwent these treatments for up to 6 weeks. Four mice were sacrificed by cervical dislocation at week 1,3 and 6 , respectively, and retinal ganglion cells were harvested. Enzyme-linked immunosorbent assay (ELISA) was used to measure nocturnal plasma MLT levels at midnight, and immunohistochemical staining was used to detect expression of the retinal MLT receptor and the expression levels of inducible nitric oxide synthase (iNOS) and c-fos protein.

The study was approved by the Ethics Committee of Qilu Hospital of Shandong University (Shandong, China).

Test method. Mice were anaesthetized by peritoneal injection of $10 \%$ chloral hydrate at midnight, the chest was quickly opened to expose the heart, and the left ventricle was punctured to collect $5 \mathrm{ml}$ of blood in EDTA anticoagulant tubes. Blood was maintained at room temperature, and centrifuged for $15 \mathrm{~min}$ at $2,500 \mathrm{x} \mathrm{g}$, the supernatant was aspirated and stored at $-80^{\circ} \mathrm{C}$ until testing.

Reagents and instruments. The MLT kit was purchased from Abcam (Cambridge, UK). Mouse monoclonal MLT receptor antibody (dilution, 1:200; catalog no. ab167108), mouse 
Table I. Comparison of the plasma levels of melatonin $(\mathrm{pg} / \mathrm{ml})$.

\begin{tabular}{|c|c|c|c|c|c|}
\hline \multirow[b]{2}{*}{ Groups } & \multicolumn{3}{|c|}{ Illumination } & \multirow[b]{2}{*}{ F-value } & \multirow[b]{2}{*}{ P-value } \\
\hline & 1 week & 3 weeks & 6 weeks & & \\
\hline A & $68.7 \pm 12.3$ & $63.5 \pm 14.2$ & $64.6 \pm 15.5$ & 0.627 & 0.538 \\
\hline B & $125.9 \pm 36.7$ & $136.2 \pm 37.8$ & $127.9 \pm 34.5$ & 0.349 & 0.126 \\
\hline $\mathrm{C}$ & $166.8 \pm 42.5$ & $172.4 \pm 40.3$ & $169.6 \pm 42.7$ & 0.528 & 0.727 \\
\hline $\mathrm{D}$ & $133.4 \pm 32.1$ & $145.5 \pm 32.6$ & $137.7 \pm 33.5$ & 0.109 & 0.935 \\
\hline F-value & 8.624 & 8.769 & 8.928 & & \\
\hline P-value & $<0.001$ & $<0.001$ & $<0.001$ & & \\
\hline
\end{tabular}

Group A had an illumination/dark time of 0 h/24 h, group B had 6 h/18 h, group C had 12 h/12 h and group D had 18 h/6 h. MLT, melatonin.

polyclonal iNOS antibody (dilution, 1:200; catalog no. ab21775) and mouse monoclonal c-fos antibody (dilution, 1:200; catalog no. ab208942) were purchased from Abcam (Cambridge, UK). SP immunohistochemistry kit was purchased from ZSGB-BIO Co., Ltd. (Beijing, China), and the diaminobenzidine (DAB) chromogenic reagent kit was obtained from Wuhan Boster Biological Technology Co., Ltd. (Wuhan, China).

Benchtop was purchased from Sunray Borui Experimental Equipment Co., Ltd. (Beijing, China), ELISA kit was purchased from Thermo Fisher Scientific, Inc. (Waltham, MA, USA), tissue slicing machine was purchased from Leica (Wetzlar, Germany), digital micropipette was purchased from Finnpipette (Vantaa, Finland), micro-ophthalmic surgical instruments were purchased from Suzhou Medical Supplies Factory Co., Ltd. (Suzhou, China), Nikon optical microscope was purchased from Nikon (Tokyo, Japan), and the Image-Pro Plus professional image analysis system (6th edition) was purchased from Media Cybernetics (Rockville, MD, USA).

ELISA. The kit was stored at room temperature $\left(20-28^{\circ} \mathrm{C}\right)$, the standards and samples for testing were added to the wells with each well containing $100 \mu$ l. Subsequently, $50 \mu 1$ of enzyme-linked affinity reagent was added to each well and mixed, the microtiter plate was covered and allowed to incubate for $60 \mathrm{~min}$ at $37^{\circ} \mathrm{C}$, and the wells were washed 5 times with cleaning solutions. Substrate I and II (50 $\mu$ l each) were successively added to each well and mixed fully at room temperature for $15 \mathrm{~min}$ in the dark. Stop solution $(50 \mu \mathrm{l})$ was then added and mixed to fully stop the reaction. The ELISA plate reader (Bio-Rad, Hercules, CA, USA) was used to read optical density (OD) values at $450 \mathrm{~nm}$, within $30 \mathrm{~min}$ and calculations for the test sample values were made by referring to the standard curve.

Tissue harvesting and processing. The eyeballs were quickly enucleated and surrounding soft tissue was removed, a small amount of freshly prepared fixing solution was injected at the edge of the corneoscleral to the vitreous chamber with a $1 \mathrm{ml}$ syringe, the eyeball was soaked in the mixed stationary liquid for $24 \mathrm{~h}$ until the tissue hardened, the cornea was cut off along the cornea ring, under a microscope (Olympus, Tokyo, Japan), and the remaining eyeball was soaked in the mixed stationary liquid to fully fix for $24 \mathrm{~h}$. It was then washed in flowing water for $24 \mathrm{~h}$, and underwent conventional gradient alcohol dehydration, and xylene paraffin embedding. The wax blocks were cut into 5 sections, with each slice cut at $4 \mu \mathrm{m}$ thickness for immunohistochemical staining. Tissue sections were placed on glass slides treated with polylysine and placed in a thermostat set to $60^{\circ} \mathrm{C}$ for $3 \mathrm{~h}$.

Immunohistochemistry. Slides were dewaxed by conventional methods, washed twice with distilled water for $5 \mathrm{~min}$, incubated in phosphate-buffered saline (PBS) for $5 \mathrm{~min}$, incubated for 10 min at room temperature with freshly prepared $3 \% \mathrm{H}_{2} \mathrm{O}_{2}$, and soaked in PBS three times for $5 \mathrm{~min}$. Slides then underwent microwave antigen retrieval. After cooling, they were washed with distilled water and blocked in normal goat serum at room temperature for $30 \mathrm{~min}$. The serum was discarded and primary antibody (1:300) was added (PBS was used as a negative control in place of primary antibody) and placed at $4^{\circ} \mathrm{C}$ for $20 \mathrm{~h}$. The slides were allowed to rewarm for $1 \mathrm{~h}$ at room temperature, and soaked in PBS four times for $5 \mathrm{~min}$. Biotin-labelled secondary antibody was added and allowed to incubate at $37^{\circ} \mathrm{C}$ for $10 \mathrm{~min}$, after which the slides underwent PBS cleaning three times for $5 \mathrm{~min}$. Horseradish peroxidase-labeled streptavidin solution (S-A/HRP) was added and incubated at $37^{\circ} \mathrm{C}$ for $10 \mathrm{~min}$, followed by PBS cleaning three times for $5 \mathrm{~min}$. DAB was added for color development and distilled water was used $10 \mathrm{~min}$ later to terminate the reaction. The slides were then counterstained with hematoxylin for $3 \mathrm{~min}$, washed with running water for $5 \mathrm{~min}$, treated with hydrochloric acid alcohol differentiation, washed for $5 \mathrm{~min}$, and treated with gradient alcohol dehydration, xylene, and neutral balata. Sections on the slides were observed under a microscope (Olympus), and we chose regions that had integrate cells and were well stained to collect data for computer input. Image-Pro Plus 6.0 was used to choose the immune yellow area in the image as AOI, to record the IOD value calculated by the software, and then to calculate the average optical density.

Statistical analysis. The data were analyzed by SPSS 19.0 statistical software (Chicago, IL, USA). Quantitative data were expressed as mean \pm standard deviation. Comparison between groups was made using one-way ANOVA test followed by post hoc test (Least Significant Difference). Enumeration data are expressed as case number or percentage, and comparisons between groups were performed using the $\chi^{2}$ test. $\mathrm{P}<0.05$ was considered to indicate a statistically significant difference. 
Table II. Relative expression levels of the melatonin receptor.

\begin{tabular}{lccccr}
\hline & \multicolumn{3}{c}{ Illumination } & \\
\cline { 2 - 4 } Groups & 1 week & 3 weeks & 6 weeks & F-value & P-value \\
\hline A & $0.09 \pm 0.02$ & $0.10 \pm 0.02$ & $0.09 \pm 0.02$ & 0.264 & 0.336 \\
B & $0.27 \pm 0.04$ & $0.32 \pm 0.06$ & $0.35 \pm 0.07$ & 6.328 & 0.019 \\
C & $0.43 \pm 0.03$ & $0.48 \pm 0.06$ & $0.54 \pm 0.05$ & 6.635 & 0.017 \\
D & $0.28 \pm 0.05$ & $0.31 \pm 0.05$ & $0.36 \pm 0.08$ & 6.269 & 0.021 \\
F-value & 9.302 & 9.426 & 9.687 & & \\
P-value & $<0.001$ & $<0.001$ & $<0.001$ & & \\
\hline
\end{tabular}

MLT, melatonin.
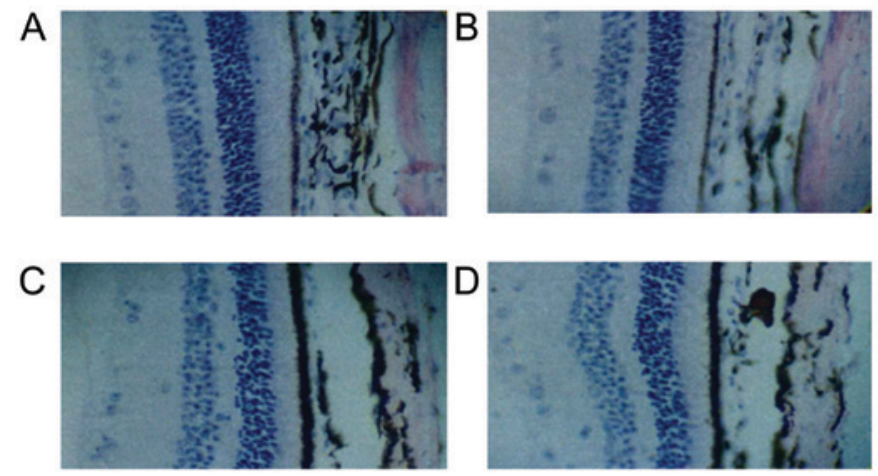

Figure 1. Expression of the melatonin (MLT) receptor by immunohistochemistry. MLT receptor levels in the groups A-D were measured by immunohistochemistry and show that levels increase with illumination time.

\section{Results}

Comparison of the plasma levels of MLT. A comparison of the light reactions of the 4 groups at week 1, 3 and 6 revealed no statistical differences $(\mathrm{P}>0.05)$. At the same time-points, group $\mathrm{C}$ had the highest MLT levels, followed by group B and group D, while group A had the lowest, and the differences were statistically significant $(\mathrm{P}<0.05)$ (Table I).

Comparison of MLT receptor expression levels. MLT receptor was stained pale brown, mainly located in the retinal pigment on the outer cortex and the kernel layer. The expression was detected inside the nucleus and cytoplasm. At each time-point, the MLT receptor expression levels of group C was the highest, followed by groups B, D and A, and the differences were statistically significant $(\mathrm{P}<0.05)$. Except for group A, the MLT receptor expression levels of the other three groups increased with illumination time, and the differences were statistically significant $(\mathrm{P}<0.05)$ (Table II and Fig. 1).

Comparison of iNOS levels. iNOS is mainly located in the retinal ganglion cell layer, inner nuclear layer, photoreceptor cell layer and choroid mesenchymal tissue. For each time-point, the iNOS level of group $\mathrm{C}$ was the lowest, followed by groups $\mathrm{B}$ and $\mathrm{D}$, while group $\mathrm{A}$ was the highest, and the differences were statistically significant $(\mathrm{P}<0.05)$ (Table III and Fig. 2).
Comparison of c-fos protein level. Expression of c-fos protein in the retina is mainly in amacrine cells and ganglion cells. For each time-point, the c-fos protein levels of group $\mathrm{C}$ was the highest, followed by groups $\mathrm{B}$ and $\mathrm{D}$, and group $\mathrm{A}$ which was the lowest, and the differences were statistically significant $(\mathrm{P}<0.05)$. Except for group $\mathrm{A}$, the MLT receptor expression levels of the three remaining groups increased with illumination time, and the differences were statistically significant $(\mathrm{P}<0.05)$ (Table IV and Fig. 3).

\section{Discussion}

The retina is the major site of synthesis of MLT apart from the epiphysis. MLT exerts an influence on the eyes through paracrine signaling. Its biosynthesis is controlled by circadian rhythm, as its secretion peaks at night and drops during the day, a process which is dually regulated by external light and the body clock (5). The MLT receptor has seven transmembrane segments, and is a member of the $\mathrm{G}$ protein-coupled receptor superfamily (6). The physiological function of MLT is to communicate information about circadian rhythms to the body in response to outside light (7). In addition, it may play an important role in immunomodulation, antioxidation, neuroprotection, and tumor inhibition (7). Furthermore, MLT may have a role in ophthalmological diseases such as diabetic retinopathy, age-related macular degeneration, glaucoma, cataract and myopia (8).

By setting different illumination times, and analyzing the regulatory mechanism of MLT in the retinal ganglion cells of healthy mice, we observed that at each time-point, group $\mathrm{C}$ had the highest MLT levels, followed by group B and D, and then by group A which had the lowest, and the differences were statistically significant, whereas in the comparison of illumination time at 1,3 and 6 weeks, there was no statistical difference in the illumination times. This suggests that the influence of circadian rhythm on MLT was greater than the illumination time (9). At each time-point, the MLT receptor expression levels of group $\mathrm{C}$ was the highest, followed by group B, group D and then by group A, and the differences were statistically significant. Apart from group A, the MLT receptor expression levels of the three remaining groups increased with illumination time, and the differences were statistically significant. This suggests that expression of the MLT receptor not only relates to circadian rhythm but also illumination time, 
Table III. Comparison of iNOS levels.

\begin{tabular}{|c|c|c|c|c|c|}
\hline \multirow[b]{2}{*}{ Groups } & \multicolumn{3}{|c|}{ Illumination } & \multirow[b]{2}{*}{ F-value } & \multirow[b]{2}{*}{ P-value } \\
\hline & 1 week & 3 weeks & 6 weeks & & \\
\hline A & $0.44 \pm 0.09$ & $0.45 \pm 0.08$ & $0.43 \pm 0.07$ & 0.946 & 0.724 \\
\hline B & $0.36 \pm 0.07$ & $0.35 \pm 0.08$ & $0.34 \pm 0.06$ & 0.638 & 0.552 \\
\hline $\mathrm{C}$ & $0.29 \pm 0.06$ & $0.27 \pm 0.07$ & $0.28 \pm 0.04$ & 0.725 & 0.639 \\
\hline $\mathrm{D}$ & $0.38 \pm 0.06$ & $0.37 \pm 0.07$ & $0.35 \pm 0.05$ & 0.526 & 0.402 \\
\hline F-value & 7.669 & 7.924 & 7.853 & & \\
\hline P-value & $<0.001$ & $<0.001$ & $<0.001$ & & \\
\hline
\end{tabular}

iNOS, inducible nitric oxide synthase.

Table IV. Expression of c-fos protein level.

\begin{tabular}{lcccr}
\hline & \multicolumn{3}{c}{ Illumination } \\
\cline { 2 - 4 } Groups & 1 week & 3 weeks & 6 weeks & F-value \\
\hline A & $0.08 \pm 0.02$ & $0.09 \pm 0.02$ & $0.07 \pm 0.02$ & 0.534 \\
B & $0.27 \pm 0.05$ & $0.32 \pm 0.06$ & $0.35 \pm 0.07$ & 6.234 \\
C & $0.36 \pm 0.05$ & $0.39 \pm 0.06$ & $0.43 \pm 0.05$ & 6.525 \\
D & $0.28 \pm 0.04$ & $0.33 \pm 0.05$ & $0.35 \pm 0.06$ & 6.317 \\
F-value & 7.968 & 8.302 & 8.421 & 0.022 \\
P-value & $<0.001$ & $<0.001$ & $<0.001$ & 0.018 \\
\hline
\end{tabular}

\section{A}
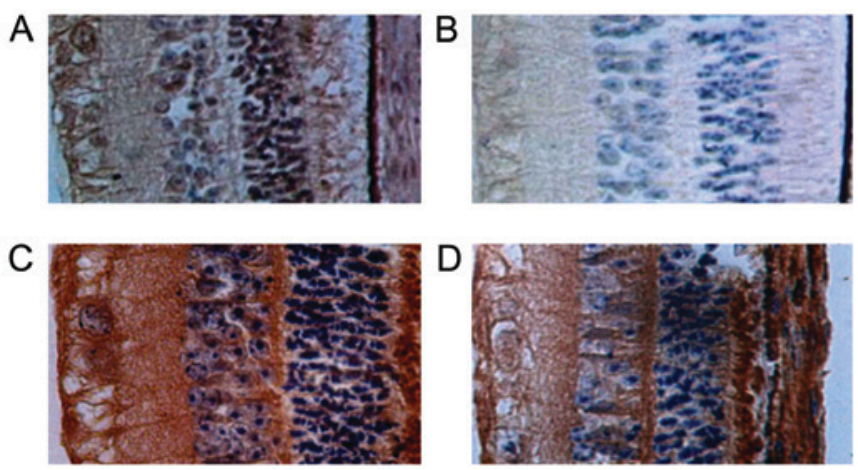

Figure 2. Expression of inducible nitric oxide synthase (iNOS) by immunohistochemistry. Levels of iNOS in groups A-D were measured by immunohistochemistry and show that they were lowest in group $\mathrm{C}$ at all time-points.

such that by extending the illumination time, the expression levels of the MLT receptor can increase (10). The comparison of iNOS levels among the different groups suggests there are no statistical differences; for each time-point, the iNOS levels of group $\mathrm{C}$ was the lowest, followed by group B and D, while highest in group A, and the differences were statistically significant. The stimulation of light makes retinal bipolar cells release the neurotransmitter glutamate. Glutamate interacts with the N-methyl-D-aspartate (NMDA) receptor on amacrine cells expressing iNOS, thus increasing internal flow of $\mathrm{Ca}^{2+}$ and iNOS activity, and increasing NO. NO can in turn, activate the soluble guanylyl cyclase (sGC) in ganglion and bipolar cells, increase cyclic guanosine monophosphate (cGMP)
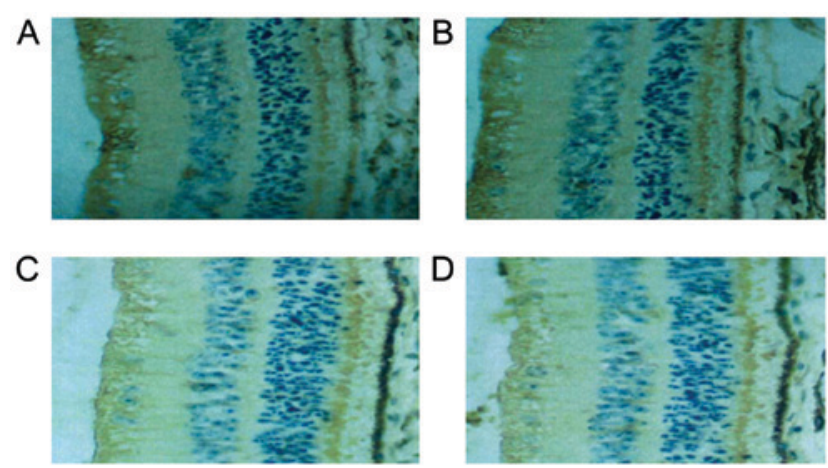

Figure 3. Expression of c-fos by immunohistochemistry. The levels of c-fos in groups A-D were measured by immunohistochemistry and show that they were highest in group $\mathrm{C}$ at all time-points.

concentrations, and produce the cGMP gating cation current. Therefore, NO possibly regulates the activity of ganglion and bipolar cells through activation of these pathways to influence the transmission of visual information (11).

At each time-point, the c-fos protein level of group $\mathrm{C}$ was the highest, followed by groups B and D, and group A which had the lowest levels. The differences were statistically significant. With the exception of group A, MLT receptor expression levels of the remaining three groups increased with illumination time, and the differences were statistically significant. The c-fos gene can be induced by second messengers, and is also called the immediate early gene (12). C-fos is upregulated in stationary cells following external stimulus. The c-fos gene 
and its protein product is not only involved in normal cellular growth and differentiation, but also participates in the process of information transmission and energy metabolism within cells (13). Hossokawa et al (14) reported that different visual stimuli induce the outer edge of the chicken hypothalamus and the inner edge of the geniculate body to upregulate c-fos expression. Aronin et al (15) showed that light changes the retinal nucleoprotein reaction level, which suggests that the expression of c-fos may be part of the 'light/dark environment' biological clock mechanism. When Zambia underground mice were treated with light stimulation, c-fos expression was found in the retina and brain (16). Light stimulation of transplanted retina can also induce c-fos expression of the mouse superior colliculus (17).

In conclusion, appropriate illumination can increase c-fos, decrease iNOS activity and regulate the physiological activities of retinal ganglion cells by regulating the expressions of MLT and its receptor. The results of the present study provide a basis for further analysis of the function of MLT on the retina under pathological conditions.

\section{References}

1. Juszczak M, Wolak M, Bojanowska E, Piera L and Roszczyk M: The role of melatonin membranereceptors in melatonin-dependent oxytocin secretion from the rat hypothalamo-neurohypophysial system - an in vitro and in vivo approach. Endokrynol Pol 67: 507-514, 2016.

2. Aranda ML, González Fleitas MF, De Laurentiis A, Keller Sarmiento MI, Chianelli M, Sande PH, Dorfman D and Rosenstein RE: Neuroprotective effect of melatonin in experimental optic neuritis in rats. J Pineal Res 60: 360-372, 2016.

3. Zetner D, Andersen LP and Rosenberg J: Melatonin as protection against radiation injury: a systematic review. Drug Res (Stuttg) 66: 281-296, 2016.

4. Gramajo AL, Marquez GE, Torres VE, Juárez CP, Rosenstein RE and Luna JD; Medscape: Therapeutic benefit of melatonin in refractory central serous chorioretinopathy. Eye (Lond) 29: 1036-1045, 2015.

5. Paulose JK, Wright JM, Patel AG and Cassone VM: Human gut bacteria are sensitive to melatonin and express endogenous circadian rhythmicity. PLoS One 11: e0146643, 2016.
6. Zhao L, Liu H, Yue L, Zhang J, Li X, Wang B, Lin Y and $\mathrm{Qu}$ Y: Melatonin attenuates early brain injury via the melatonin

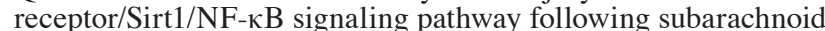
hemorrhage in mice. Mol Neurobiol 54: 1612-1621, 2017.

7. Shimada M, Seki H, Samejima M, Hayase M and Shirai F: Salivary melatonin levels and sleep-wake rhythms in pregnant women with hypertensive and glucose metabolic disorders: a prospective analysis. Biosci Trends 10: 34-41, 2016.

8. Agorastos A and Huber CG: The role of melatonin in glaucoma: implications concerning pathophysiological relevance and therapeutic potential. J Pineal Res 50: 1-7, 2011.

9. Tan DX, Manchester LC and Reiter RJ: CSF generation by pineal gland results in a robust melatonin circadian rhythm in the third ventricle as an unique light/dark signal. Med Hypotheses 86: 3-9, 2016

10. Comai S, Ochoa-Sanchez R, Dominguez-Lopez S, Bambico FR and Gobbi G: Melancholic-like behaviors and circadian neurobiological abnormalities in melatonin $\mathrm{MT}_{1}$ receptor knockout mice. Int J Neuropsychopharmacol 18: 123-125, 2015.

11. Overs $\varnothing$ Hansen P, Kringelholt S, Simonsen U and Bek T: Hypoxia-induced relaxation of porcine retinal arterioles in vitro depends on inducible $\mathrm{NO}$ synthase and $\mathrm{EP}_{4}$ receptor stimulation in the perivascular retina. Acta Ophthalmol 93: 457-463, 2015

12. Tanuri FC, de Lima E, Peres MF, Cabral FR, da Graça Naffah-Mazzacoratti M, Cavalheiro EA, Cipolla-Neto J, Zukerman E and Amado D: Melatonin treatment decreases c-fos expression in a headache model induced by capsaicin. J Headache Pain 10: 105-110, 2009.

13. Oshitari T, Yamamoto S and Roy S: Increased expression of c-Fos, c-Jun and c-Jun N-terminal kinase associated with neuronal cell death in retinas of diabetic patients. Curr Eye Res 39: 527-531, 2014.

14. Hossokawa NM, Araki CM, Hamassaki-Britto DE, Wallman J and Britto LR: Expression of the Fos protein reveals functional subdivisions of the avian ventral lateral geniculate nucleus. Neurosci Lett 218: 53-56, 1996.

15. Aronin N, Sagar SM, Sharp FR and Schwartz WJ: Light regulates expression of a Fos-related protein in rat suprachiasmatic nuclei. Proc Natl Acad Sci USA 87: 5959-5962, 1990.

16. Oelschläger HHA, Nakamura $\mathrm{M}$, Herzog $\mathrm{M}$ and Burda $\mathrm{H}$ : Visual system labeled by c-Fos immunohistochemistry after light exposure in the 'blind' subterranean Zambian mole-rat (Cryptomys anselli). Brain Behav Evol 55: 209-220, 2000.

17. Matejů K, Sumová A and Bendová Z: Expression and light sensitivity of clock genes Perl and Per2 and immediate-early gene $c$-fos within the retina of early postnatal Wistar rats. J Comp Neurol 518: 3630-3644, 2010. 